\title{
Guidelines on authorship
}

\author{
INTERNATIONAL COMMITTEE OF MEDICAL JOURNAL EDITORS
}

Reprinted by kind permission of the Editor of the British Medical Journal of September 141985

At its last meeting the International Committee of Medical Editors (the Vancouver group) drew up the following guidelines on authorship and on other contributions that should be acknowledged. The committee also expanded the section on information to be given in the covering letter to include details of any conflict of interest and clarify the position of the author responsible for final approval of proofs. These guidelines will be incorporated into the Uniform Requirements for the Submission of Manuscripts to Biomedical Journals ${ }^{1}$ when it is next revised.

\section{GUIDELINES ON AUTHORSHIP}

Each author should have participated sufficiently in the work to take public responsibility for the content. This participation must include: $(a)$ conception or design, or analysis and interpretation of data, or both; $(b)$ drafting the article or revising it for critically important intellectual content; and (c) final approval of the version to be published. Participation solely in the collection of data does not justify authorship.

All elements of an article ( $a, b$, and $c$ above) critical to its main conclusions must be attributable to at least one author.

A paper with corporate (collective) authorship must specify the key persons responsible for the article; others contributing to the work should be recognised separately (see Acknowledgments and other information).

Editors may require authors to justify the assignment of authorship.

\section{ACKNOWLEDGMENTS OF CONTRIBUTIONS}

THAT FALL SHORT OF AUTHORSHIP

At an appropriate place in the article (title page, footnote, or appendix to the text; see journal's requirements) one or more statements should specify: (a) contributions that need acknowledging but do not justify authorship, $(b)$ acknowledgments of technical help, $(c)$ acknowledgments of financial and material support, and $(d)$ financial relationships that may constitute a conflict of interest.

Persons who have contributed intellectually to the paper but whose contribution does not justify authorship may be named and their contribution described-for example, "advice," "critical review of study proposal," "data collection," "participation in clinical trial." Such persons must have given their permission to be named.

Technical help should be acknowledged in a separate paragraph from the contributions above.

Financial or material support from any source must be specified. If a paper is accepted it may also be appropriate to include mention of other financial relationships that raise a conflict of interest, but initially these should be outlined in the covering letter.

\section{INFORMATION TO BE INCLUDED IN THE COVERING LETTER}

Manuscripts must be accompanied by a covering letter. This must include: $(a)$ information on prior or duplicate publication or submission elsewhere or any part of the work; $(b)$ a statement of financial or other relationships that might lead to a conflict of interests; (c) a statement that the manuscript has been read and approved by all authors; and $(d)$ the name, address, and telephone number of the corresponding author, who is responsible for communicating with the other authors about revisions and final approval of the proofs.

The manuscript must be accompanied by copies of any permissions to reproduce published material, to use illustrations of identifiable persons, or to name persons for their contributions.

\footnotetext{
${ }^{1}$ International Committee of Medical Journal Editors. Uniform requirements for manuscripts submitted to biomedical journals. Br Med J 1982;284:1766-70.
}

Members of the committee are: Dr A Blum, New York State Journal of Medicine, New York; Dr A Brass, Medical Journal of Australia, Sydney; Dr O Harlem, Norwegian Medical $\omega$ Journal, Oslo; Dr E Huth (co-secretary), Annals of Internal Medicine, Philadelphia; Dr SP Lock (co-secretary), British Medical Journal, London; Dr G Lundberg, Journal of the $\frac{C}{\mathbb{D}}$ American Medical Association, Chicago; Dr P Morgan, $\stackrel{\infty}{\rightarrow}$ Canadian Medical Association Journal, Ottawa; Dr I Munro, The Lancet, London; Dr A Relman, New England Medical Journal, Boston; Dr P Riis, Danish Medical Journal, $\overrightarrow{\mathbb{D}}$ Copenhagen; Dr R Robinson, New Zealand Medical Jour- $\mathcal{\rho}$ nal, Dunedin; Dr I Vartiovaara, Finnish Medical Journal, § Helsinki.

$$
\text { . }
$$

